\title{
"Female representation in games": uma proposta de unidade didática com base na translinguagem para a aula de língua inglesa
}

Dêner da Silva Ramos*

Anamaria Welp ${ }^{* *}$

\section{Resumo}

O presente artigo tem por objetivo apresentar uma unidade didática (UD) elaborada para a aula de língua inglesa como língua adicional de uma turma de oitavo ano do ensino fundamental. Apoiada no ensino e aprendizagem de língua adicional com base em tarefas, a UD tem como temática principal a representação de personagens femininas em jogos eletrônicos e o gênero minibiografia como proposta de produção final. Nesse contexto, a discussão se ancorou na noção de repertório linguístico e sua relação com a translinguagem e na teoria sociocultural e o processo de andaimento no ensino de língua adicional. $\mathrm{O}$ artigo descreve as tarefas e suas recomendações de aplicação e procura demonstrar como o trabalho com a translinguagem em aulas de língua adicional pode ser um importante recurso para aproximar o aluno da língua que está aprendendo.

Palavras-chave: Translinguagem; Andaimento; Unidade didática.

\section{Introdução}

A presença de diversas línguas em espaços sociais é um fenômeno recorrente na contemporaneidade. O desenvolvimento das tecnologias impulsionou a expansão da informação e, consequentemente, 0 contato entre as línguas. No que se refere ao inglês, é comum encontrarmos textos, em diferentes suportes, cujos elementos verbais estão no próprio idioma. Muitas vezes, mesmo a língua portuguesa estando presente, aparece associada ao inglês.

García (2017) afirma que esses fatos apontam para o surgimento de novos de-

\footnotetext{
Mestrando em Linguística Aplicada pelo Programa de Pós-graduação em Letras da Universidade Federal do Rio Grande do Sul (UFRGS) e Professor de Língua Inglesa da Prefeitura Municipal de Viamão - RS. E-mail: denersramos@gmail.com

** Doutora em Letras pelo Programa de Pós-graduação em Letras da Pontifícia Universidade Católica do Rio Grande do Sul (PUCRS) e Professora Associada do Instituto de Letras da Universidade Federal do Rio Grande do Sul (UFRGS). E-mail: anamaria.welp@ ufrgs.br
}

Data de submissão: dez. 2020 - Data de aceite: mar. 2021 http://dx.doi.org/10.5335/rdes.v17i01.11386 
safios na educação, uma vez que a escola deve estar em contato constante com as mudanças da sociedade. Nesse sentido, a autora sugere a utilização de todo o repertório linguístico do aluno na prática pedagógica do professor. Através desse recurso, os alunos lançam mão de todos os elementos das línguas que conhecem de forma integrada para a construção de conhecimento. Assim, as línguas que o aluno já domina não são hierarquizadas, na medida em que todas têm um importante papel no processo de ensino e aprendizagem. García (2009) define essa estratégia pedagógica como translinguagem.

Ainda hoje, nas escolas, é comum se ouvirem frases como "por que vou aprender inglês se nunca vou usar na vida e nem sair do país?" (SCHLATTER; GARCEZ, 2009), o que revela o desconhecimento do aluno em relação às vantagens de se dominar uma língua adicional. Nesse contexto, partindo-se de tal premissa, argumenta-se que a translinguagem na aula de língua adicional na escola pública é uma estratégia de ensino que potencialmente aproxima o aluno do conteúdo, ou, como afirma Schlatter (2009, p. 12), pode levá-lo a "reconhecer a língua estrangeira em um texto escrito ou oral e não virar as costas a esse texto".

$\mathrm{O}$ presente artigo tem por objetivo apresentar uma unidade didática (doravante UD) para a aula de língua inglesa, embasada pela translinguagem (GARCÍA, 2017), considerando a pers- pectiva de Schlatter e Garcez (2009) sobre o ensino/aprendizagem de língua adicional com base em tarefas. O público-alvo considerado para sua criação foi o oitavo ano do ensino fundamental. $\mathrm{O}$ artigo inicia discutindo a noção de repertório linguístico (BUSCH, 2012) e de translinguagem (GARCÍA, 2017). Em seguida, faz-se uma breve discussão sobre a teoria sociocultural (VYGOTSKY, 1991) e scaffolding como aportes teóricos para a elaboração de tarefas. A seguir, são descritas a UD e as instruções para sua aplicação. Por fim, são apresentadas as considerações finais.

\section{Translinguagem, repertório linguístico e ensino de língua adicional}

Para um melhor entendimento do conceito de translinguagem na aula de língua adicional, faz-se necessário entender as noções de repertório linguístico. Conforme Busch (2012), o termo vem do que Gumperz $(1960,1964)$ entende como repertório verbal, que é definido pelo indivíduo conforme a interação social que se dá em determinado contexto, significando que $o$ falante de uma língua utiliza sua cultura, trajetória de vida, memórias e a variação da língua necessários para a comunicação em um dado contexto. Esse repertório liga-se a uma comunidade discursiva, que contém "todos os tipos de formulações de mensagens aceitáveis" (BUSCH, 
2012, p. 2). Entende-se, portanto, que o repertório linguístico compreende, além de línguas e dialetos que um indivíduo domina, aqueles elementos que ele necessariamente usa para fazer sentido em um contexto discursivo.

Para aprofundar a definição, Busch (2012) apoia-se no conceito de super diversidade, cunhado por Vertovec (2007), de forma a sustentar a ideia de que $o$ repertório linguístico é constituído de contextos discursivos e de gramática. A super diversidade é descrita como um fenômeno que trata da expansão global da mobilidade que dá origem a novas e crescentes formações sociais (BUSCH, 2012). Estas últimas resultam em práticas interligadas, isto é, ações que ocorrem quando os indivíduos de um contexto discursivo estão desterritorializados, uma vez que o crescimento tecnológico permite diferentes interações sociais sem a necessidade de que duas pessoas ocupem o mesmo espaço físico. Nesse sentido, o indivíduo entra em contato com mais variedades linguísticas de quaisquer línguas, envolvendo-se com práticas diferentes daquelas que já conhecia.

Nessa perspectiva, entende-se que há uma relação com a capacidade de cada indivíduo de mobilizar a língua para agir no mundo, noção desenvolvida por Clark (2004). Segundo o autor, utilizamos a língua para interagir com o mundo, fazendo coisas, desempenhando ações e papéis em determinados contextos. Tais ações, ou práticas sociais, ocorrem justamente pelo uso da língua. O repertório linguístico, portanto, é utilizado nas práticas sociais, de modo que faça sentido para o contexto discursivo em que está sendo mobilizado (CLARK, 2004; BUSCH, 2012).

Associada a esse conceito, a translinguagem surge como uma estratégia pedagógica importante na aula de língua adicional, pois sua utilização permite que o espaço de aprendizagem compreenda o repertório linguístico de todos os participantes (GARCÍA, 2017). Com isso, em uma aula de língua adicional, o aluno utiliza a língua que já domina com a finalidade de se apropriar do idioma que está aprendendo, possibilitando sua aproximação com esse novo idioma sem que a primeira língua seja apagada ou considerada um problema no processo de aprendizagem (GARCÍA, 2017).

De acordo com García (2017), os propósitos para o uso da translinguagem na aula de língua adicional se relacionam com as necessidades dos alunos em aprender uma nova língua. Para a autora, dar suporte aos alunos para que eles se engajem com e compreendam textos e conteúdos complexos é fundamental na medida em que se estabeleça uma transição entre diferentes contextos (GARCÍA, 2017). Dessa forma, os alunos têm a oportunidade de desenvolver práticas linguísticas presentes em gêneros acadêmicos, usando as línguas que sabem e criando um espaço para o bilinguismo. Portanto, geram-se condições 
para o desenvolvimento socioemocional dos alunos e para a construção de sua identidade bilíngue (GARCÍA, 2017).

Considerando a translinguagem, portanto, como uma estratégia de ensino, alunos e professores podem recorrer a seus repertórios como uma forma de realizar práticas sociais, de forma que a aprendizagem e o ensino ocorram por meio da criatividade e do olhar crítico (GARCÍA, 2017). O repertório do aluno não se limita a uma língua ou outra: a sala de aula passa a ser um ambiente em que o repertório linguístico é utilizado sem restrições. Dessa maneira, a translinguagem funciona como uma ponte entre uma língua e outra, o que remete ao sociointeracionismo de Vygotsky (1991), tema da próxima seção deste artigo.

\section{Teoria sociocultural e scaffolding}

Através de sua Teoria Sociocultural, Vygotsky (1991) explica os processos de desenvolvimento e aprendizagem da criança. Para ilustrar seu ponto de vista, o autor utiliza o exemplo de uma criança que tenta alcançar uma lata de biscoitos que está fora de seu alcance. Percebendo que não consegue realizar a tarefa sozinha, a criança observa atentamente o lugar em que se encontra na busca de algum objeto que possa ajudá-la a atingir seu objetivo. Ao deparar-se com uma vara, automaticamente percebe que pode usá-la para alcançar a lata. Para Vygotsky (1991), o processo inteiro permite que consideremos a importância da interação na aprendizagem da criança.

$\mathrm{O}$ autor postula que os processos de aprendizagem ocorrem na interação do indivíduo com o mundo mediada por artefatos físicos e simbólicos (LANTOLF; THORNE; POEHNER, 2015; NEGUERUELA-AZAROLA; GARCÍA, 2016). No exemplo em questão, a vara consiste no artefato físico e, considerando que a língua é usada para organizar o pensamento, ela se torna o artefato simbólico, que medeia a interação da criança com seu objetivo, ou seja, a lata de biscoitos. Dessa forma, o processo de construção de conhecimento ocorrido na interação, até o momento em que se atinge o objetivo, pode se repetir em outras situações de aprendizagem.

Vygotsky (1991) supõe a existência de um espaço entre aquilo que a criança pode realizar sozinha e o que ela pode realizar com o auxílio de alguém mais experiente. Segundo o autor, é nesse espaço que a aprendizagem ocorre. Ressalta-se, entretanto, que, para Vygotsky (1991), aprendizado não é o mesmo que desenvolvimento. Embora ambos os processos estejam relacionados, o desenvolvimento somente se dá após o aprendizado ser efetivado, ou seja, ele resulta em desenvolvimento, e este último desencadeia uma série de outros processos complexos que permitem que a criança utilize o 
conhecimento adquirido em outros contextos de aprendizagem. Vygotsky (1991) define esse espaço como Zona de Desenvolvimento Proximal (doravante ZDP).

Como forma de explicar os processos de aprendizagem que ocorrem na ZDP, Gibbons (2015) emprega o conceito de scaffolding, que em português pode ser traduzido como "andaimento". Para a autora, o andaimento é um processo cuja função é preencher a ZDP com estruturas, ou "andaimes". Tal processo ocorre por meio da interação entre dois indivíduos: ambos constroem andaimes de forma recíproca, interagindo mutuamente e construindo conhecimento de forma colaborativa (GIBBONS, 2015).

No contexto escolar, os andaimes podem ser vistos como as estratégias construídas pelo professor e pelos alunos para se chegar a um objetivo. Nesse sentido, Gibbons (2015) pontua que o ensino e aprendizagem de língua adicional devem ocorrer em espaços em que o uso da língua seja autêntico. Por essa razão, o trabalho pedagógico deve ser norteado pelo uso da língua de maneira contextualizada e com propósitos sociais, e os textos devem ser selecionados a partir de determinadas esferas da sociedade, como um texto jornalístico de um renomado jornal, por exemplo (GIBBONS, 2015). Assim, o professor desenha tarefas pedagógicas que permitem que os alunos criem andaimes, interagindo significativamente e se ajudando mutuamente.

\section{Construção da unidade didática}

A UD foi desenvolvida para uma aula de língua inglesa do oitavo ano do ensino fundamental e tem como tema principal a representatividade de figuras femininas nos jogos de videogame. Para tanto, conta com o gênero ${ }^{1}$ minibiografia, em português e em inglês, valendo-se da translinguagem com o propósito de oferecer oportunidades para que o aluno crie um caminho entre seu repertório linguístico e a língua alvo (VYGOTSKY, 1991; GIBBONS, 2015; GARCÍA, 2017).

Em consonância com Schlatter e Garcez (2009) e Filipouski, Marchi e Simões (2009), foram elaboradas tarefas a partir de textos que circulam na temática pré-estabelecida, sendo que são compreendidas: 1) Tarefas Preparatórias, cuja função é ativar conhecimento prévio sobre o tema; 2) Tarefas de Contato Inicial com o Texto, para preparar o aluno para a leitura do texto; 3) Tarefas de Leitura, em que o aluno é levado a reconhecer informações importantes durante a leitura; 4) Tarefas de Compreensão Sobre o Texto, para que o aluno reflita sobre o texto, construindo seu ponto de vista sobre sua temática a partir de importantes informações provenientes do texto; 5) Tarefas de Reflexão sobre o Texto, em que os alunos são colocados em momentos de interação para fazer sentido do que leem; 6) Tarefas de Reflexão Linguística, para que haja um contato 
reflexivo com recursos linguísticos de maneira contextualizada; 7) Tarefas de Contato com o Gênero, para que o aluno identifique as características do gênero que irá produzir; e 8) Tarefa de Produção, em que o aluno utiliza os conhecimentos mobilizados ao longo da unidade para a criação de uma produção final.

\section{A unidade didática e as sugestões para sua aplicação}

Nesta seção justificamos a escolha da temática e as discussões desejadas na aplicação da UD, e apresentamos as tarefas com as sugestões para sua aplicação.

\section{A escolha da temática}

Como anteriormente mencionado, a UD tem como temática a representação de personagens femininas nos jogos eletrônicos. A escolha dessa temática se dá devido à recorrente presença de personagens femininas no mundo dos jogos eletrônicos. Entretanto, com frequência, nesse universo, essas personagens são representadas de maneira hipersexualizada, trajando vestimentas reveladoras, com destaque a atributos físicos, com ênfase em partes do corpo, como seios, quadris, glúteos, coxas, em detrimento de características como coragem, inteligência, astúcia, força de caráter, etc. Para Araújo e Pereira (2017, p. 1), “esse tipo de representação reforça estereótipos já propagados em outras mídias, como os polêmicos comerciais de cerveja".

O problema dessa representação não está somente no fato de as imagens serem fruto do ideário masculino e, portanto, distantes da realidade, mas sobretudo por serem os jogos substancialmente populares entre jovens, que estão sujeitos à sua influência e, portanto, expostos a estereótipos indesejáveis, que reproduzem padrões de beleza inatingíveis e objetificam e desrespeitam o público feminino. Torna-se então necessário descontruir essas representações equivocadas e, através do desenvolvimento da criticidade, tornar a aula de línguas um espaço de combate ao preconceito e da valorização da mulher.

A personagem escolhida para guiar a elaboração da UD foi Lara Croft, protagonista da série de jogos Tomb Raider. A franquia, lançada em 1996, foi uma das primeiras a ter como protagonista uma personagem feminina, dando origem ao "fenômeno Lara". No seu rastro, surgiram no universo dos games outras heroínas em posição de liderança e ocupando um espaço que costumava ser exclusivamente masculino (ARAÚJO, 2018).

A série de jogos versa sobre a jovem arqueóloga britânica, que, em suas missões, vive diversas aventuras. Segundo Araújo (2018), com tantas possibilidades de representação que seriam coerentes com a narrativa da personagem - entre 
outras coisas, Lara explora tumbas, descobre civilizações perdidas, resgata amuletos e itens preciosos -, os produtores optaram por retratar a heroína seguindo um padrão de feminilidade estereotipado. Para Araújo e Pereira (2017, p. 2),

Lara Croft corresponde aos ideais de beleza e feminilidade ocidentais, dentre eles seios grandes, cintura fina, lábios carnudos, pernas de fora, e por mais que ela represente uma mudança nos jogos, ao colocar uma mulher como protagonista, sua inserção ainda é problemática por ser apresentada de forma sexualizada e dentro de um padrão de beleza, atraindo o público masculino para o jogo, pelos motivos errados.

Somente em 2013 Lara foi apresentada com características mais realistas e naturais, com um visual mais coerente com sua narrativa. Por essa razão, ao pensar na transição das representações da personagem através dos anos, a he- roína foi selecionada para fazer parte das discussões propostas na UD.

\section{Sugestão para a aplicação da UD}

Para uso efetivo da translinguagem, todas as instruções e enunciados da UD estão em português e inglês. Com o propósito de evitar a acomodação e a preferência do aluno pela leitura somente das partes em português, é imprescindível que o professor saiba conduzir o trabalho pedagógico de forma que ambos os idiomas sejam utilizados na construção de sentido.

A UD inicia com um parágrafo introdutório ao tema, que pode ser lido silenciosamente com a turma. A leitura do parágrafo tem o objetivo de preparar os alunos para as discussões sobre o tema, envolvendo, portanto, a ativação de conhecimento prévio.

Quadro 1. O Início da UD

FEMALE REPRESENTATION IN GAMES: AN INITIAL DISCUSSION

A lot of female characters have starred in video games these days and most of them are portrayed as strong and independent women. Yet, stereotypes are present. In this unit, we are going to read a text about a female video game hero so that we can have a talk about how female characters are or how they should be represented in games. We are also going to talk about a verb tense in English and the "mini biography" genre. Note that the instructions are in English and Portuguese to help you understand the tasks. Use the Portuguese instructions to understand the English instructions whenever it is necessary.
REPRESENTAÇÃO FEMININA NOS JOGOS ELETRÔNICOS: UMA DISCUSSÃO INICIAL

Muitas personagens femininas têm protagonizado jogos de videogame atualmente e a maioria delas é retratada como mulheres fortes e independentes. Ainda assim, estereótipos estão presentes. Nesta unidade, vamos ler um texto sobre uma heroína dos games para que possamos conversar sobre como as personagens femininas são ou como deveriam ser representadas nos games. Também vamos conversar sobre um tempo verbal em inglês e o gênero "minibiografia". Note que as instruções estão em inglês e português para ajudá-lo a entender as tarefas. Use as instruções em português para entender as instruções em inglês se necessário.

Fonte: elaborado pelos autores 
Após a leitura, o professor deve ressaltar que as instruções estão em dois idiomas. Pode também conduzir um pequeno brainstorming sobre o conceito da palavra stereotypes.
Em seguida, na tarefa preparatória, o professor deve pedir que os alunos se juntem em duplas e leiam as instruções, sempre frisando a importância da leitura nas duas línguas. Esta tarefa objetiva preparar os alunos para a temática da unidade.

Quadro 2. Tarefa 1

\section{BEGINNING THE DEBATES}

1) In this unit, you are going to meet an important female figure in video games. Before we start, talk to the classmate beside you and discuss the following questions:

a) Do you know any female protagonists in video games? Which ones?

b) What do you think about games that have female protagonists?

c) When you play games, do you prefer playing with female or male characters? Why?

\section{COMEÇANDO OS DEBATES}

1) Nesta unidade, você vai conhecer uma importante figura feminina nos video-games. Antes de começar, converse com o colega ao seu lado e discuta as seguintes questões:

a) Você conhece alguma protagonista feminina em video games? Quais?

b) $O$ que você pensa sobre jogos que têm protagonistas femininas?

c) Quando você joga, você prefere jogar com personagens femininas ou masculinas? Por quê?

Fonte: elaborado pelos autores

Após a discussão introdutória, parte-se para a tarefa de contato inicial com o texto. O professor deve solicitar que os alunos observem as três imagens diferentes de Lara Croft:

\section{Quadro 3. Tarefa 2}

\begin{tabular}{|l|l|}
\hline BEFORE YOU READ THE TEXT & ANTES DE LER O TEXTO \\
2) Now, look at the following pictures and answer: & 2) Agora, olhe para as seguintes fotos e responda: \\
\hline
\end{tabular}
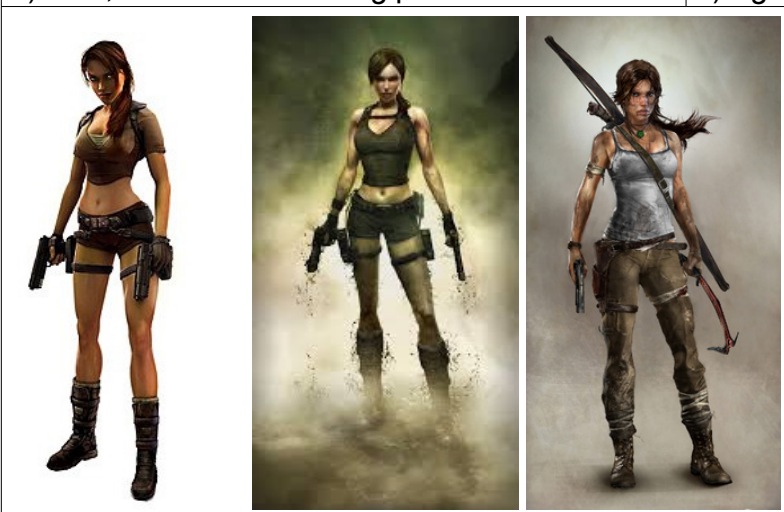

Fontes:

https://pt.wikipedia.org/wiki/Lara_Croft

https://br.pinterest.com/pin/307933693246622888/

https://en.wikipedia.org/wiki/Lara_Croft

Fonte: elaborado pelos autores 
Esse material deve ser mostrado de acordo com os recursos disponíveis na escola. Caso a escola não disponha de um projetor, podem ser feitas cópias ou um cartaz de cartolina com as fotos expostas. Para analisar as fotos, ainda em duplas, os alunos devem discutir as seguintes questões:

\section{Quadro 4. Tarefa 2}

\begin{tabular}{|l|l|}
\hline $\begin{array}{l}\text { a) Compare the pic- } \\
\text { tures. What do you think } \\
\text { about these women? }\end{array}$ & $\begin{array}{l}\text { a) Compare as fotos. O } \\
\text { que você acha sobre es- } \\
\text { sas mulheres? }\end{array}$ \\
$\begin{array}{ll}\text { b) What do you think } \\
\text { about the way they are } \\
\text { pictured? What does it } \\
\text { say about the charac- }\end{array}$ & $\begin{array}{l}\text { bão que representadas? O } \text { quensa isso diz sobre as } \\
\text { ter? What, in your opin- }\end{array}$ \\
$\begin{array}{l}\text { ion, is the most promi- } \\
\text { nent characteristic ex- }\end{array}$ & $\begin{array}{l}\text { em sua opinião, é a ca- } \\
\text { racterística mais notável }\end{array}$ \\
pressed in the pictures? & expressada nas fotos? \\
\hline
\end{tabular}

Fonte: elaborado pelos autores

Essa tarefa, além de preparar os alunos para a leitura de um texto sobre a persona- gem, também os instiga a pensar sobre as diferenças existentes entre as fotos em relação à sua representação, buscando assim estimular o pensamento crítico em relação à forma estereotipada como personagens femininas são representadas em videogames. O professor deve proporcionar um determinado espaço de tempo para que os alunos discutam as questões e, em seguida, iniciar uma discussão geral, elegendo algumas duplas para falar sobre o que discutiram. Nesse momento, o professor pode falar em inglês e em português, para que torne o ambiente confortável para os alunos fazerem o mesmo.

Ao finalizar a tarefa, o próximo momento da aula é a realização da leitura do texto. O professor deve solicitar aos alunos que façam a leitura, primeiramente, de forma individual e silenciosa ao realizar a tarefa:

Quadro 5. Tarefa 3

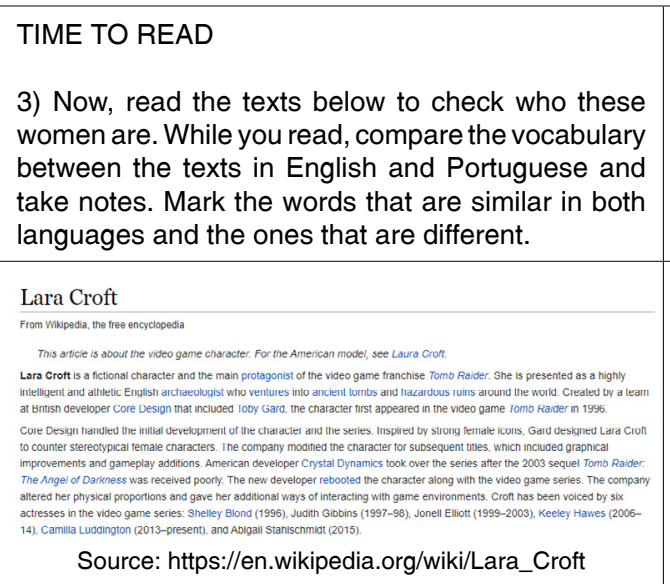

Fonte: elaborado pelos autores

\section{HORA DE LER}

3) Agora, leia os textos abaixo para verificar quem são essas mulheres. Enquanto você lê, compare o vocabulário entre os textos em inglês e português e faça anotações. Marque as palavras que são parecidas em ambas as línguas. e naquelas que são diferentes.

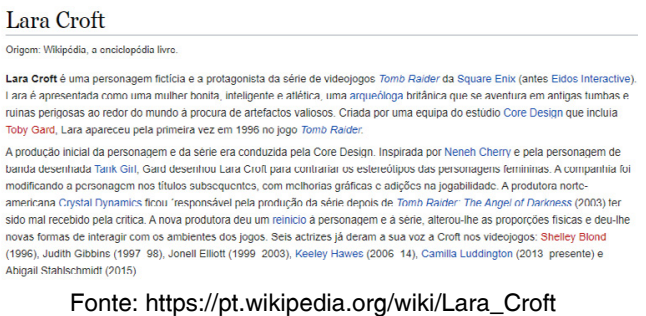
Fonte: https://pt.wikipedia.org/wiki/Lara_Croft 
Em seguida, o professor deve solicitar que os alunos se organizem novamente em duplas e realizem a tarefa final deste bloco:

\section{Quadro 6. Tarefa 3}

\begin{tabular}{|l|l|}
\hline a) After reading & a) Depois da leitura \\
the texts, compare & dos textos, compare as \\
your notes with your & suas anotações com as \\
classmate's and & do seu colega e verifi- \\
check new vocabu- & que o novo vocabulário \\
lary you both found. & que vocês encontraram.
\end{tabular}

Fonte: elaborado pelos autores

Essa tarefa tem o propósito de promover o trabalho com o vocabulário por meio de interação com o texto e com o colega, e de garantir que o aluno leia o texto nas duas línguas. Para finalizar esta etapa, pode-se realizar uma conversa sobre as palavras encontradas, sistematizando exemplos no quadro, em inglês e português.

A próxima etapa da unidade consiste em uma tarefa de compreensão do texto. O professor deve, neste momento, estabelecer um determinado espaço de tempo para que os alunos se juntem novamente. É importante que ele enfatize que os alunos devem realizar a tarefa conjuntamente, respondendo as seguintes questões:

Quadro 7. Tarefa 4

UNDERSTANDING THE TEXTS

4) With a classmate, answer the following questions about the texts:

a) Who is the videogame character?

b) What does she do?

c) Who is the character's creator?

d) What was his inspiration for creating the character?

e) Considering the images and the texts, do you think the character is based on female stereotypes? Which ones?

f) If you were the creator of Lara Croft, how would you portray her? What characteristics of the character would you highlight? Explain your choice.

\section{ENTENDENDO OS TEXTOS}

4) Junto com um colega, responda as seguintes questões sobre o texto:

a) Quem é a personagem de videogame?

b) O que ela faz?

c) Quem é o criador da personagem?

d) Qual foi a sua inspiração para criar a personagem?

e) Considerando as imagens e os textos, você acha que a personagem é baseada em estereótipos femininos? Quais?

f) Se você fosse o criador de Lara Croft, de que forma você a retrataria? Que características da personagem vocês destacaria? Explique sua escolha.

Fonte: elaborado pelos autores

Ao finalizar esta tarefa, o professor deve relacioná-la com a próxima, cujo propósito é suscitar uma reflexão sobre o texto. Nesse momento, os alunos são convidados a se posicionar criticamente sobre a temática da unidade partindo da tarefa de compreensão do texto. O professor deve pedir aos alunos que formem trios, se possível, e discutam as questões anotando as conclusões a que chegaram. 
Quadro 8. Tarefa 5

DISCUSSING THE TEXT

5) Considering what you read about the character and the answers from exercise 4, get together in trios and discuss the following topics:

a) The text is about Lara Croft's design. By looking at both pictures, talk about her female representation in the game. Do you think there is a difference between the ways she is portrayed in the three pictures? Why?

b) Talk about female characters representation and female stereotypes in games: how different is Lara from other female videogame characters?

c) Do you think Lara's look is consistent with her identity? Explain your answer.

After this, discuss your ideas with the whole group.
DISCUTINDO O TEXTO

5) Considerando o que você leu sobre a personagem e as respostas do exercício 4, junte-se em trios e discuta os seguintes tópicos:

a) O texto trata sobre o desenvolvimento de Lara Croft. Examinando as fotos, converse sobre sua representação feminina em jogos de videogame. Você acha que existe uma diferença no modo em que ela é retrata das três fotos? Por quê?

b) Converse sobre a representação de personagens femininas e sobre estereótipos femininos nos games: o quão diferente Lara Croft é de outras personagens femininas nos videogames?

c) Você acha que o visual de Lara é coerente com sua identidade? Explique sua resposta.

Após isso, discuta suas ideias com a turma inteira.

Fonte: elaborado pelos autores

Durante o debate, sugere-se que o professor encoraje o uso de todo o repertório linguístico dos alunos. Vale ressaltar que, embora seja importante que se faça uso da língua alvo, o professor não deve apagar a primeira língua do aluno em seu processo de construção de sentido do texto e de apropriação de seu conteúdo.

A próxima etapa trata da tarefa de reflexão linguística. $\mathrm{O}$ tempo verbal de maior predominância no texto em inglês é o passado simples regular, utilizado para falar de eventos e fatos que aconteceram com a personagem no passado e que estão finalizados. Com o objetivo de ampliar o repertório linguístico do aluno através da utilização de sua primeira língua para fazer sentido do texto, a translinguagem foi a estratégia considerada nesta tarefa, que teve como propósito sugerir comparações entre os tempos do passado em inglês e em português. Assim, o trabalho pedagógico foi organizado em quatro partes.

A primeira trata de oferecer ao aluno um primeiro contato com o tempo verbal, retomando parte do texto e conduzindo questionamentos para uma reflexão inicial: 
Quadro 9. Tarefa 6

TIME TO UNDERSTAND THE LANGUAGE IN USE

6) Take a look at this part of the text in English. Pay close attention to the verbs and how they work:
HORA DE ENTENDER A LÍNGUA EM USO

6) Observe esta parte do texto em inglês. Preste bem $a$ atenção nos verbos e em como eles funcionam:

Core Design handled the initial development of the character and the series. Inspired by strong female icons, Gard designed Lara Croft to counter stereotypical female characters. The company modified the character for subsequent titles, which included graphical improvements and gameplay additions. American developer Crystal Dynamics took over the series after the 2003 sequel Tomb Raider: The Ange/ of Darkness was received poorly. The new developer rebooted the character along with the video game series. The company altered her physical proportions and gave her additional ways of interacting with game environments. Croft has been voiced by six actresses in the video game series: Shelley Blond (1996), Judith Gibbins (1997-98), Jonell Elliott (1999-2003), Keeley Hawes (200614), Camilla Luddington (2013-present), and Abigail Stahlschmidt (2015).

Fonte: https: https://en.wikipedia.org/wiki/Lara_Croft

Now, read the same part in the Portuguese version and answer:

Agora, leia a mesma parte na versão em Português e responda:

a) Is the paragraph written in the Present, Past or Future?

a) O parágrafo está escrito no Presente, Passado ou Futuro?

b) How can you tell that? Check the verbs below taken from the texts to find the answer. Compare the verbs in English and in Portuguese.

b) Como você percebe isso? Olhe para os verbos abaixo retirados do texto para encontrar a resposta. Compare os verbos em inglês e português.

\begin{tabular}{|c|c|}
\hline VERBS IN ENGLISH & VERBS IN PORTUGUESE \\
\hline DESIGNED & DESENHOU \\
\hline MODIFIED & MODIFICOU \\
\hline ALTERED & ALTEROU \\
\hline
\end{tabular}

Fonte: elaborado pelos autores

Essa tarefa pode ser realizada individualmente, em duplas ou em pequenos grupos. $\mathrm{O}$ importante é que o professor faça questionamentos aos alunos e analise junto deles os verbos em português e em inglês. Em seguida, a segunda parte da tarefa consiste na compreensão do uso do tempo passado simples regular e na identificação da regra geral para formação de verbos no passado em inglês em comparação com o português: 
Quadro 10. Tarefa 7

7) TALKING ABOUT FINISHED EVENTS: If you thought the paragraph was about past events, you were right. As you can see, in English, regular verbs in the Past Simple tense have the same termination, no matter the person. Unlike Portuguese, in which the end of the verbs varies according to the person, in English, we use the -ED at the end of most verbs to form the past.

\begin{tabular}{|l|l|}
\hline & \multicolumn{1}{|c|}{ INGLÊS } \\
\hline & \\
DESIGN $>$ I designed Lara Croft. \\
You designed Lara Croft. \\
She designed Lara Croft. \\
DESIGNED \\
He designed Lara Croft. \\
It designed Lara Croft. \\
We designed Lara Croft. \\
They designed Lara Croft Croft.
\end{tabular}

a) Can you tell the difference between verbs in the past in Portuguese and in English? Talk to your classmates to check the answers.
7) FALANDO SOBRE EVENTOS PASSADOS: Se você pensou que o parágrafo estava falando sobre eventos passados, você estava certo. Como você pode ver, em inglês os verbos no tempo passado simples são conjugados com a mesma terminação, não importa a pessoa. Diferentemente do português, em que os verbos variam sua terminação conforme a pessoa em que o verbo é conjugado, em inglês, nós usamos o -ED no final da maioria dos verbos para formar o passado:

PORTUGUÊS

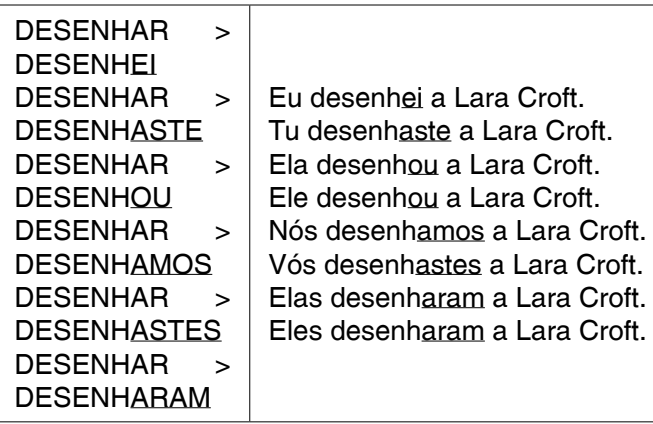

a) Você sabe dizer qual a diferença entre os verbos no passado em português e em inglês? Converse com os seus colegas para verificar suas respostas.

Fonte: elaborado pelo autor

O professor pode esboçar no quadro os esquemas dos verbos em inglês e em português para que todos visualizem a comparação. A questão final pode ser realizada brevemente diante de toda a turma para que em seguida inicie a terceira parte da tarefa de reflexão linguística. 
Quadro 11. Tarefa 8

8) HOW TO USE THE PAST IN ENGLISH: the Past Simple is used to express actions or events that happened once and will not happen again, that is, it is used to talk about finished actions or events in the past. Take a look at the example extracted from the text:

Gard designed Lara Croft [...]

The company modified the character for the subsequent titles [...]

Source: https://en.wikipedia.org/wiki/Lara_Croft

When we read the first example, we understand that Gard designed Lara in the past. In the second sentence, we understand that the modifications on Lara were also done and finished in the past.

a) Considering these examples, answer: why is the past simple being used in this text? If the text were written in the present, do you think it would have the same meaning? Why?
8) COMO USAR O PASSADO EM INGLÊS: O Passado Simples é usado para expressar eventos que ocorreram apenas uma vez e não vão acontecer novamente, isto é, para falar sobre ações ou eventos que já terminaram no passado. Dê uma olhada no exemplo extraído do texto:

Gard designed Lara Croft [...]

The company modified the character for the subsequent titles [...]

Fonte: https://en.wikipedia.org/wiki/Lara_Croft

Quando lemos o primeiro exemplo, entendemos que Gard desenhou Lara no passado. Na segunda sentença, entendemos que as modificações na Lara também foram realizadas e finalizadas no passado.

a) Considerando esses exemplos, responda: por que o passado simples está sendo utilizado neste texto? Se o texto fosse escrito no presente, você acha que ele teria o mesmo sentido? Por quê?

Fonte: elaborado pelos autores

Por meio dessa tarefa, os alunos são levados a questionar o motivo por que o texto é construído com verbos no passado. Essa parte pode ser realizada em pequenos grupos e, após, ser discutida com toda a turma.

$\mathrm{Na}$ sequência, o professor deve conduzir os alunos à última parte da tarefa de reflexão linguística, que, apesar de consistir em um exercício de preenchimento de lacunas, retoma o texto da UD em língua portuguesa para que o aluno identifique e produza, em língua inglesa, o passado simples, lançando mão de seu repertório para ajustar o discurso a um interlocutor que compreenda o conteúdo em inglês. É importante ressaltar que as frases utilizadas nessa tarefa foram provenientes de um texto autêntico, ou seja, que não foi produzido exclusivamente como pretexto para ensinar o recurso linguístico trabalhado, de forma que o aluno tenha contato com o uso real do tempo verbal de forma contextualizada.

A próxima tarefa pode ser desempenhada individualmente ou em duplas: 
Quadro 12. Tarefa 9

\begin{tabular}{|c|c|}
\hline $\begin{array}{l}\text { 9) TIME TO PRACTICE! } \\
\text { Read the text in Portuguese once again. }\end{array}$ & $\begin{array}{l}\text { 9) HORA DE PRATICAR } \\
\text { Releia o texto em português. }\end{array}$ \\
\hline \multicolumn{2}{|l|}{ Lara Croft } \\
\hline \multicolumn{2}{|c|}{$\begin{array}{l}\text { Lara é apresentada como uma mulher bonita, inteligente e atlética, uma arqueóloga britânica que se aventura em antigas tumbas e } \\
\text { ruínas perigosas ao redor do mundo à procura de artefactos valiosos. Criada por uma equipa do estúdio Core Design que incluía } \\
\text { Toby Gard, Lara apareceu pela primeira vez em } 1996 \text { no jogo Tomb Raider. }\end{array}$} \\
\hline \multicolumn{2}{|c|}{$\begin{array}{l}\text { A produção inicial da personagem e da série era conduzida pela Core Design. Inspirada por Neneh Cherry e pela personagem de } \\
\text { banda desenhada Tank Girl, Gard desenhou Lara Croft para contrariar os estereótipos das personagens femininas. A companhia foi } \\
\text { modificando a personagem nos titulos subsequentes, com melhorias gráficas e adições na jogabilidade. A produtora norte- } \\
\text { americana Crystal Dynamics ficou 'responsável pela produção da série depois de Tomb Raider: The Angel of Darkness (2003) ter } \\
\text { sido mal recebido pela critica. A nova produtora deu um reinicio à personagem e à série, alterou-lhe as proporções fisicas e deu-lhe } \\
\text { novas formas de interagir com os ambientes dos jogos. Seis actrizes já deram a sua voz a Croft nos videojogos: Shelley Blond } \\
\text { (1996), Judith Gibbins (1997-98), Jonell Elliott (1999-2003), Keeley Hawes (2006-14), Camilla Luddington (2013-presente) e } \\
\text { Abigail Stahlschmidt (2015). }\end{array}$} \\
\hline \multicolumn{2}{|l|}{ Fonte: https://pt.wikipedia.org/wiki/Lara_Croft } \\
\hline $\begin{array}{l}\text { Now, use the verbs in the box to complete the } \\
\text { sentences in English with information from the } \\
\text { text in Portuguese. Remember to use the past } \\
\text { form of the verbs! }\end{array}$ & $\begin{array}{l}\text { Agora, use os verbos no quadro para completar } \\
\text { as frases em inglês com informações retiradas do } \\
\text { texto em português. Lembre-se de usar o passa- } \\
\text { do dos verbos! }\end{array}$ \\
\hline \multicolumn{2}{|c|}{ MODIFY EXCLUDE HANDLE APPEAR REBOOT DESIGN } \\
\hline \multicolumn{2}{|c|}{$\begin{array}{l}\text { a) "the character first } \_ \text {in the video game Tomb Raider in 1996." } \\
\text { b) "Core Design the initial development of the character and the series." } \\
\text { c) "Gard Lara Croft to counter stereotypical female characters." } \\
\text { d) "The new developer__ the character along with the movie series" } \\
\text { e) "The company the character for subsequent titles." } \\
\text { f) "The new developer_the character along with the video game series" }\end{array}$} \\
\hline
\end{tabular}

Fonte: elaborado pelos autores

Após a finalização do momento de reflexão linguística, a UD começa a se encaminhar para a produção final dos alunos. Portanto, o professor deve iniciar a tarefa de contato com o gênero que a turma irá produzir para que os alunos analisem suas características e se familiarizem com o gênero. Esta tarefa deve ser realizada em duplas, e os alunos devem observar os textos e verificar as informações a seguir: 
Quadro 13. Tarefa 10

STUDYING THE TEXT!

10) Now, it is time to study the mini biography genre! Read the texts again and take notes of the following characteristics:

a) Character's main information, such as name, birthplace, personality, etc.

b) Facts about the character, such as her job, her creator, etc.

c) If the text is written in the 1st or the 3rd person.

d) The verb tenses used and the one that is most used.

e) The facts reported in the text: are they about the character? Are they about the character's creation? Describe the information you find in both languages Portuguese and English.
ESTUDANDO O TEXTO!

10) Agora, é hora de estudar o gênero minibiografia! Leia os textos novamente e tome notas das seguintes características:

a) As informações mais importantes da personagem, como o nome, local de nascimento, personalidade, etc.

b) Fatos sobre a personagem, como sua profissão, seu criador, etc.

c) Se o texto está escrito na primeira ou na segunda pessoa.

d) Os tempos verbais utilizados e aquele que é mais utilizado.

e) Os fatos relatados no texto: eles são sobre a personagem? Eles são sobre a criação da personagem? Descreva as informações em português e inglês.

Fonte: elaborado pelos autores

O professor deve estabelecer um determinado espaço de tempo para que os alunos desempenhem a tarefa. Em seguida, a turma inteira pode discutir sobre suas conclusões. É importante que, neste momento, o professor sistematize as informações no quadro para que todos tenham acesso ao que foi discutido.
A última tarefa é a de produção, momento da UD em que os alunos mobilizarão os conhecimentos previamente construídos para escrever um texto do gênero minibiografia. O professor deve pedir que cada um construa seu texto individualmente, em língua inglesa.

Quadro 14. Tarefa 11

CREATING YOUR MINI BIOGRAPHY

11) After the discussions about Lara Croft and how female characters are represented in games, it is time for you to write a mini biography, in English, about one female character from video games that you like. If you don't play videogames, you can choose any other female character from other media. To produce your text, you are going to use the Past Simple to talk about past events of the chosen character.
CRIANDO SUA MINIBIOGRAFIA

11) Depois das discussões sobre Lara e sobre como personagens femininas são representadas nos games, é hora de você escrever uma minibiografia, em inglês, sobre alguma personagem feminina de videogames de que você goste. Se você não joga videogames, você pode escolher qualquer outra personagem feminina de outra mídia. Para produzir o seu texto, você vai usar o Passado Simples para escrever sobre os eventos passados da personagem que você escolher.

Fonte: elaborado pelos autores 
É importante reforçar que o aluno deve recorrer a todos os aspectos que foram trabalhados e construídos durante a UD para a criação do texto. Como a tarefa pede que os alunos escolham uma personagem para construir sua minibiografia, eles precisarão de tempo para pesquisar as informações. Portanto, a tarefa pode ser realizada fora da sala de aula, com a utilização de computadores, caso a escola disponha de um laboratório de informática, ou de dicionários, mas sempre sob a supervisão do professor.

Ao final da tarefa, o professor deve recolher os textos para uma primeira avaliação, apontando os ajustes necessários e sugerindo alterações para melhor adequação ao gênero. Ao finalizar as reescritas, os alunos podem criar um painel, na escola, para publicar seus textos. Se houver a possibilidade de se utilizarem meios tecnológicos disponíveis, os alunos podem criar uma página em alguma rede social para a publicação de seus textos.

\section{Considerações finais}

O presente artigo apresentou uma UD, cuja temática versa sobre a representação de personagens femininas nos jogos eletrônicos, construída para uma turma do oitavo ano do ensino fundamental. Partindo-se da aprendizagem com base em tarefas (SCHLATTER; GARCEZ, 2009) e da translinguagem (GARCÍA, 2017), a UD foi elaborada tendo por base a formulação de que o aluno pode utilizar todo o seu repertório linguístico para construir o conhecimento na língua que está aprendendo.

Conforme Schlatter (2009), a aula de língua adicional deve promover a reflexão e a autonomia do aluno na "busca por uma compreensão de sua própria realidade e de uma ampliação de sua participação em práticas sociais" que se fazem na língua que está sendo aprendida. Nesse sentido, relativo ao desenho de tarefas, a translinguagem, como estratégia pedagógica, auxilia os alunos a relacionarem o novo aprendizado à sua realidade de forma crítica, através da valorização e da ampliação do repertório linguístico que trazem consigo (GARCÍA; JOHNSON; SELTZER, 2017).

Segundo levantamento conduzido pelo British Council (2014), apenas 5\% da população brasileira se reconhece como falante de inglês. Considerando essa realidade, o ensino de línguas adicionais ainda se apresenta como um desafio para a maior parte da população brasileira (BRITISH COUNCIL, 2019). Dessa forma, o uso da translinguagem na aula de língua adicional tem o potencial de aproximar a nova língua do aluno, permitindo-lhe enxergar-se como pertencente ao grupo de falantes dessa língua e "reconhecer a língua estrangeira em um texto escrito ou oral e não virar as costas a esse texto" (SCHLATTER, 2009, p. 12). 
Ademais, a teoria sociocultural e o scaffolding (VYGOTSKY, 1991; GIBBONS, 2015) desempenham um papel fundamental na construção de tarefas translíngues. O processo de aproximar o aluno de uma língua adicional utilizando como recurso todo o seu repertório linguístico requer a construção de UDs, cujo embasamento se dê a partir da interação na aprendizagem. Nesse sentido, as tarefas, estruturadas por tais processos interativos, conduzem os alunos na construção conjunta de conhecimento.

\section{Female representation in games": a didactic unit proposal for the English language lesson based on translanguaging}

\section{Abstract}

this article presents a didactic unit (DU) designed for an English as an additional language class addressed to eighth graders in secondary school. Supported by task-based learning for additional language teaching, the DU's main theme is the representation of female characters in videogames and the mini-biography genre as the final production proposal. In this context, the discussion was anchored in the concept of linguistic repertoire and its relationship with translanguaging, as well as on the sociocultural theory and scaffolding in additional language teaching. The article describes the tasks and their application and seeks to demonstrate how working with translanguaging in additio- nal language classes can be an important resource to bring the language learner closer to the new language.

Keywords: Translanguaging; Scaffolding; Didactic unit.

\section{Notas}

1 Conforme Bakhtin (2010), os gêneros do discurso são "tipos relativamente estáveis de enunciados" (p. 262), o que significa que suas condições de existência dependem das práticas sociais que ocorrem através do uso a língua. Esses gêneros podem originar novos gêneros, se alterar ou se renovar à medida que a sociedade se modifica, e assim originar novas práticas sociais. Nessa perspectiva, a minibiografia, portanto, é vista como um gênero porque depende das condições em que é produzida e que a caracterizam como tal.

\section{Referências}

ARAÚJO, G. P. C. Fight like a girl: O protagonismo feminino nos jogos digitais. Revista Sistemas e Midias Digitais (RSMD), vol. 3, n. 1, p. 1-16, 2018.

ARAÚJO, G. P. C.; PEREIRA, G. C. Não se preocupem queridos, a cavalaria chegou: análise crítica do design das personagens de Overwatch. In: SBGames, 2017, Curitiba. Anais Eletrônicos do XVI Simpósio Brasileiro de Jogos e Entretenimento Digital, Paraná: PUC-PR, 2017, p. 17-26.

BAKHTIN, M. Estética da criação verbal. São Paulo: Martins Fontes, 2010.

BUSCH, B. The Linguistic Repertoire Revisited. Applied Linguistics, Oxford, vol. 33, n.5, p. 503-523, 2012.

BRITISH COUNCIL. Políticas públicas para o ensino de inglês: um panorama das experiências na rede pública brasileira. São Paulo: British Council Brasil, 2019. 
BRITISH COUNCIL. Learning English in Brazil Understanding the aims and expectations of the Brazilian emerging middle classes. São Paulo: British Council Brasil, 2014.

CLARK, H. H. O uso da linguagem. Cadernos de Tradução, n. 9, Porto Alegre, p. 55-80, 2000.

FILIPOUSKI, A. M. R.; MARCHI, D. M.; SIMÕES, L. J. Língua Portuguesa e Literatura. In: RIO GRANDE DO SUL, SECRETARIA DO ESTADO DE EDUCAÇÃ̃O. Referenciais curriculares do Estado do Rio Grande do Sul: linguagens, códigos e suas tecnologias. Porto Alegre: SE/DP, 2009.

GARCÍA, O.; JOHNSON, S. I.; SELTZER, $\mathrm{K}$. The translanguaging classroom. Philadelphia: Caslon, 2017.

GIBBONS, P. Scaffolding Language, Scaffolding Learning - Teaching English Language Learners in the Mainstream Classroom. Postmouth: Heinemann, 2015.

GUMPERZ, J. J. Formal and informal standards in Hindi regional language area (with $\mathrm{C}$. M. Naim). International Journal of American Linguistics, Vol. 3, n. 23, p. 92-118, 1960.

GUMPERZ, J. J. Linguistic and social interaction in two communities. American Anthropologist, Vol. 66, n. 6, p. 137-53, 1964.

LANTOLF, J. P.; THORNE, S. L.; POEHNER, M. E. Sociocultural Theory and Second Language Development. In: VANPATTEN, B.; WILLIAMS, J. (Org.). Theories in Second Language Acquisition: An introduction. Nova Iorque: Routledge, p. 207-227, 2015.

NEGUERUELA-AZAROLA, E.; GARCÍA, P. N. Sociocultural theory and the language classroom. In: HALL, G. (Org). The Routledge Handbook of English Teaching. Nova Iorque: Routledge, p. 295-309, 2016.

SCHLATTER, M.; GARCEZ, P. M. Línguas Adicionais (Espanhol e Inglês). In: RIO GRANDE DO SUL, SECRETARIA DO ESTADO DE EDUCAÇÃO. Referenciais Curriculares do Estado do Rio Grande do
Sul: Linguagens, Códigos e suas tecnologias. Porto Alegre: SE/DP, 2009.

VERVOTEC, S. Super-diversity and its implications. Ethnic and Racial Studies, vol. 29, n.6, p. 1024-1054, 2007.

VYGOTSKY, L. S. A Formação Social da Mente. São Paulo: Martins Fontes Editora, 1991. 